\title{
EL ACCESO LIMITADO A LA JUSTICIA ADMINISTRATIVA FRENTE A LOS REQUISITOS DE PROCEDIBLIDAD*
}

\section{THE LIMITED ACCESS TO ADMINISTRATIVE VERSUS WITH THE PROCEDURAL REQUIREMENT}

Manuel David Jaramillo Duque**:

\section{Resumen:}

En el presente artículo se analiza críticamente el acceso a la justicia administrativa teniendo en cuenta el diseño normativo de la Ley 1437 de 2011 y la nueva regulación de la suspensión provisional de los actos administrativos. Se pretende demostrar, a partir del análisis jurisprudencial, que el derecho de acceso a la justicia administrativa no se encuentra garantizado de manera eficaz. Esto debido a los diferentes requisitos de procedibilidad que se deben agotar para poder ejercer el derecho de acción, tales como la reclamación administrativa previa y la conciliación prejudicial. Y por otra parte, debido a que dentro del

Recibido: 13 de marzo de 2017 - Aprobado: 30 de noviembre de 2017.

* Artículo inédito.

Tiene como fundamento teórico la investigación realizada por el autor: JARAMILLO, Manuel. "Razón de Estado o Estado de razón. La justificación constitucional de los privilegios de la administración pública en Colombia: El privilegio de la decisión previa", 2017, Bogotá, Universidad Nacional de Colombia. http://www.bdigital.unal.edu. co/57643/1/1088262399.2017.pdf

Para citar el artículo: JARAMILLO DUQUE, Manuel David. El acceso limitado a la justicia administrativa frente a los requisitos de procediblidad. Revista del Instituto Colombiano de Derecho Procesal. No. 46 Julio - Diciembre. 2017, pp. 183-203.

** Abogado de la Universidad Libre, Especialista en Derecho Administrativo de la Universidad del Rosario, Especialista en Derecho Constitucional de la Universidad Nacional y Magíster en Derecho de la Universidad Nacional. Contacto: manueldjd@hotmail.com 
El acceso limitado a la justicia administrativa frente a los requisitos de procediblidad

contexto judicial la posibilidad de lograr la suspensión provisional implica agotar trámites judiciales que no superan en eficacia a la acción de tutela. Demostrando, además, como la acción de tutela ha sido declarada improcedente ante el falso argumento de la idoneidad y eficacia del medio de control de nulidad y restablecimiento del derecho.

Palabras claves: Suspensión provisional de los actos administrativos, acceso a la justicia administrativa, acción de tutela, conciliación prejudicial, reclamación administrativa previa.

\begin{abstract}
This article analyzes critically the access to administrative justice, taking into account the normative design of law 1437 of 2011 and the new regulation of the provisional suspension of administrative acts. It is tried to demonstrate, from the jurisprudential analysis, that the right of access to the administrative justice is not guaranteed in an effective way. This is due to the different procedural requirements that must be exhausted in order to exercise the right of action, such as the prior administrative complaint and preliminary conciliation. And on the other hand, because within the judicial context, the possibility of achieving the provisional suspension involves exhausting judicial procedures that are not outdated in effectiveness to the writ of protection of constitutional rights. Proving further, how the writ of protection of constitutional rights has been declared inadmissible before the false argument of the suitability and effectiveness of the means of nullity control and reestablishment of the right.
\end{abstract}

Key words: Provisional suspension of administrative acts, access to administrative justice, writ of protection of constitutional rights, prior administrative complaint and preliminary conciliation.

\title{
Introducción
}

La Constitución Política de Colombia, como norma de normas, garantiza en su artículo 229 el derecho de acceso a la administración de justicia, esto es, la facultad de poner en movimiento el aparato jurisdiccional del Estado con el fin de hacer efectivos los derechos, obligaciones, garantías y libertades de las personas, y mantener la convivencia social y la concordia nacional.

La jurisprudencia de la Corte Constitucional ha desarrollado este derecho, que además es un principio y un valor, desde una perspectiva amplia y garantista, resaltando las obligaciones de respetar, proteger y realizar los derechos humanos.

No obstante, cuando se analiza el desarrollo normativo de este derecho en la Ley 1437 de 2011 -Código de Procedimiento Administrativo y de lo Contencioso 
Administrativo (CPACA)-, se observa una regulación limitada, poco garantista, enfocada a retardar, e, incluso, impedir la posibilidad de acceder a la jurisdicción de lo contencioso administrativo.

Ahora bien, el CPACA estableció una nueva regulación de la suspensión provisional de los actos administrativos, que, en comparación con la regulación que consagraba el Decreto 01 de 1984 -Código Contencioso Administrativo (CCA)-, ofrece algunos avances normativos importantes.

En el año 2005, en el contexto normativo del CCA, un sector de la doctrina manifestaba que, si bien la legislación preveía la existencia de las medidas cautelares, la regulación de la tutela cautelar judicial resultaba insuficiente dentro del marco garantista de la Constitución Política vigente ${ }^{1}$. Para concluir lo anterior, se argumentaba que "si la razón de ser de las medidas cautelares es evitar la consumación de un daño jurídico derivado de un retraso en la decisión judicial definitiva, en el proceso contencioso administrativo el panorama es desolador, ya que en él la única tutela cautelar judicial es la suspensión provisional del acto administrativo, regulada demás en términos muy restrictivos"2. Por esta razón, se indicaba la necesidad de reformar las medidas cautelares del CCA, con el fin de garantizar la eficacia de las decisiones judiciales, como parte del derecho a la tutela judicial efectiva y como una forma de salvaguardad la seguridad jurídica. Y para cumplir tal objetivo era necesario ampliar las medidas cautelares, desde el punto de vista cuantitativo y cualitativo.

El legislador atendió tales consideración, y contempló un nuevo diseño normativo de las medidas cautelares en el proceso contencioso administrativo a través de la expedición del CPACA. Algunos autores indican que el capítulo del CPACA relativo a las medidas cautelares incorpora "uno de los más trascendentales cambios en materia contencioso administrativa" ${ }^{3}$. En relación con la regulación anterior de la suspensión provisional, se afirma que su "eficacia práctica era muy poca, dados los límites y requisitos legales y jurisprudenciales instituidos para el efecto"4. En este sentido, uno de los avances más importantes de la nueva regulación del CPACA consisten en que "la nueva normatividad ya no determina la procedencia sobre la base de la "manifiesta infracción", esto es

$1 \quad$ RESTREPO, Manuel. "La necesidad de ampliar la tutela cautelar judicial en el proceso contencioso administrativo", No. 7 (2) Revista Estudios Socio-Jurídicos, 2005, Bogotá, Universidad del Rosario, p. 202.

2 Ibíd., p. 196.

3 GONZÁLEZ, Sergio, "Capítulo XI - Medidas Cautelares", Código de Procedimiento Administrativo y de lo Contencioso Administrativo, Ley 1437 de 2011, comentado y concordado, Primera edición, Bogotá, Universidad Externado de Colombia, 2013, p. 490.

$4 \quad$ Ibíd. 
El acceso limitado a la justicia administrativa frente a los requisitos de procediblidad

infracción grosera, de bulto, observada prima facie, de las disposiciones invocadas, por "confrontación directa o mediante documentos públicos aducidos con la solicitud", lo que restringía notablemente el campo de acción de tal medida. El nuevo ordenamiento prevé, de manera más flexible, que basta que se presente la violación de las disposiciones invocadas cuando tal violación surja del análisis del acto demandado y su confrontación con las normas esgrimidas como violadas o del estudio de "las pruebas"-ya no únicamente documentos públicos-allegados".

En similar sentido, se ha indicado que "con la expedición de la Ley 1437 de 2011 se buscó fortalecer los poderes del juez a fin de lograr esta protección, ya que dentro de la jurisdicción contenciosa administrativa la única cautela posible era la suspensión provisional de los efectos del acto administrativo. Esto, además de resultar insuficiente, era de difícil aplicación por la rigurosidad de sus requisitos. Razón por la cual la citada norma no sólo incluye nuevas medidas cautelares, sino que también flexibilizó los requerimientos de la existente a fin de hacer más fácil su aplicación"6.

A pesar de lo anterior, la evaluación de la nueva regulación de las medidas cautelares en el proceso contencioso administrativo no debe ser realizada sin tener en cuenta el contexto normativo para acceder a la jurisdicción que establece el CPACA.

Un caso paradigmático es el de la nulidad de un acto administrativo de carácter particular. Para promover la nulidad de un acto administrativo particular es necesario agotar el recurso administrativo obligatorio, que por regla general es el de apelación, y también es necesario agotar la conciliación prejudicial. Esto quiere decir que, para poder demandar y pedir la suspensión provisional de un acto administrativo particular, es necesario agotar una serie de requisitos de procedibilidad que le restan eficacia a la nueva regulación de las medidas cautelares.

Por ello, la nueva regulación de la suspensión provisional no ofrece garantías de acceso eficaz a la jurisdicción, pues no deja de estar enmarcada en una normatividad enfocada a retardar y, en algunos casos, impedir el acceso a la administración de justicia en el escenario de la jurisdicción de lo contencioso administrativo.

Bajo esta perspectiva, en el presente escrito se busca determinar si el desarrollo legislativo del acceso a la administración de justicia en el ámbito de la jurisdicción de lo contencioso administrativo, es coherente con los parámetros constitucionales

Ibíd., pp. 495-496.

6 GARCÍA, Yezid, GÓMEZ, Lina, PUENTES, Elizabeth, "El nuevo régimen de las medidas cautelares contempladas en la Ley 1437 de 2011 y su aplicación en la jurisdicción contenciosa administrativa". Derecho y Políticas Públicas, Volumen 16 No. 20. Bogotá, Universidad Cooperativa de Colombia, 2014, p. 37. dx.doi.org/10.16925/ di.v16i20.833 30 de abril de 2017. 
o si, por el contrario, la legislación desborda lo ordenado constitucionalmente, desconociendo la fuerza normativa de la Constitución Política de 1991.

Para cumplir lo anterior se presentan tres capítulos. En el primero se aborda el concepto de constitución normativa y la forma como la jurisprudencia de la Corte Constitucional ha entendido el derecho de acceso a la administración de justicia. En el segundo capítulo, se profundiza en los requisitos que se deben surtir para acceder a la jurisdicción de lo contencioso administrativo, enfocado en la pretensión de nulidad y restablecimiento del derecho. En el tercer capítulo, se analiza la suspensión provisional de los actos administrativos y su relación con la acción de tutela. Finalmente se presentan las conclusiones.

\section{La Constitución Política, su fuerza normativa y el acceso a la jurisdicción administrativa}

La Constitución Política de 1991 posee un carácter normativo y prevalente dentro del ordenamiento jurídico, tal como se desprende de su artículo 4, según el cual la Constitución es norma de normas, y en todo caso de incompatibilidad entre la Constitución y la ley u otra norma jurídica, se aplicarán las disposiciones constitucionales.

La fuerza normativa de la Constitución Política se refiere a la obligatoriedad de sus disposiciones, y a su capacidad de vincular a los particulares y a las autoridades públicas. La jurisprudencia de la Corte Constitucional ha señalado que, en virtud de la fuerza normativa de la Constitución, "las autoridades no solo se hallan sometidas al derecho positivo presidido por la norma superior, en el ejercicio de sus competencias; también para la realización efectiva de los derechos subjetivos consagrados constitucionalmente, ante dichas autoridades pueden los ciudadanos exigir la realización efectiva de los derechos constitucionales" ${ }^{\prime \prime}$. Es decir, existe un texto positivo de la más alta jerarquía normativa, acompañado de instrumentos de protección que garantizan su cumplimiento.

Según la doctrina, la fuerza normativa implica que la Constitución Política "no es sólo un documento político, sino una norma que vincula especialmente al legislador y por vía indirecta al ejecutivo, y que, por consiguiente, debe tener algún mecanismo que garantice su supremacía y su carácter obligatorio -esto es, alguna forma de justicia constitucional para proteger la norma fundamental contra vulneraciones por parte del legislador o del ejecutivo"s.

7 Colombia, Corte Constitucional. Sala Plena. Sentencia de Constitucionalidad C-415, 6 de junio de 2012, MP. Mauricio González Cuervo, Expediente No. D-8820.

8 UPRIMNY, Rodrigo, RODRÍGUEZ, César. "Constitución y modelo económico en Colombia: hacia una discusión productiva entre economía y derecho". Debates de coyuntura económica. Bogotá. 2006, p. 25. 
El acceso limitado a la justicia administrativa frente a los requisitos de procediblidad

Por lo anterior, la fuerza normativa de la Constitución Política de 1991 consiste en su capacidad de vincular a las autoridades públicas y a los particulares, estableciendo, además, los mecanismos necesarios para su cumplimiento. De esta manera, la función judicial es garantía del cumplimiento efectivo de la Constitución Política.

Siguiendo a Gargarella, se puede criticar la actitud de creer que la simple consagración o ampliación de derecho y libertades es suficiente para su garantía, sin tener en cuenta la necesidad de acompañar esa consagración o ampliación de derechos y libertades con reformas en la estructura del poder público. En otras palabras, la ampliación o consagración de derechos es insuficiente si no se modifica la organización del poder.

Refiriéndose a los límites de las reformas que sólo buscan ampliar derechos, sin reformar el poder público, Gargarella indica que "uno de los límites más significativos es, justamente, el de haber concentrado las energías del cambio en la sección de derechos, sin reconocer la influencia que (tal como examináramos más arriba), se ejerce sobre ellos desde la sección constitucional dedicada a la organización del poder. Al actuar de este modo los lideres del reformismo social parecen asumir que la potencia transformativa del Derecho es tal, que la mera inclusión de ciertas cláusulas constitucionales resulta autooperativa: basta con incorporar ciertos cambios en la Constitución, para que ellos cobren vía, se autoejecuten". 9

Según lo anterior, los derechos proclamados constitucionalmente tienen la capacidad de incidir en la realidad si se acompañan de reformas en la estructura del poder público. Siguiendo esta idea general, se puede señalar que es necesario un diseño de la rama jurisdiccional dirigido a garantizar los derechos constitucionales formalmente consagrados, para transitar de una constitución retórica, semántica o nominal hacia una constitución con verdadera fuerza normativa.

La diferencia entre esta tipología de constituciones, normativas, nominalistas y semánticas, puede ser analizada a partir de Marcelo Neves, quien, siguiendo a Loewenstein, indica que las constituciones normativas son aquellas con la capacidad de direccionar realmente el proceso del poder, de manera que las relaciones políticas, y los agentes de poder, quedan sometidos a las determinaciones materiales y procesales de la constitución. Las constituciones nominalistas, si bien consagran disposiciones de limitación y control del poder político, no tienen la capacidad de direccionar el proceso real de poder, no existiendo suficiente concretización constitucional. Por último, las constituciones semánticas son un simple reflejo de la realidad del proceso político, que

9 GARGARELLA, Roberto. "El constitucionalismo latinoamericano y la "sala de máquinas" de la Constitución (1980-2010)”. Gaceta Constitucional No. 48. Bogotá. 2011, p. 302. 
sirven, al contrario que las normativas, como instrumento de los dueños del poder, sin incidir en la limitación y control del poder político ${ }^{10}$

La relación entre lo retórico y lo normativo ha sido explicada por Mauricio García mediante el concepto de constitucionalismo aspiracional. Según este autor, el constitucionalismo aspiracional ha prosperado en situaciones donde hay una gran inconformidad con el presente, y una gran expectativa por un futuro mejor. Así mismo, busca la efectividad fáctica y no meramente jurídica de sus normas. Esa efectividad se contempla mediante dos vías: 1. La movilización política. 2. El control judicial de las leyes y actos administrativos ${ }^{11}$.

El constitucionalismo aspiracional genera tensiones interinstitucionales entre mayorías políticas y los jueces. Adicional a ello, el constitucionalismo aspiracional requiere algo más que el simple desarrollo legal o jurisprudencial, requiere el compromiso de los movimientos sociales, es decir, un constitucionalismo militante, así como la consolidación de una nueva cultura jurídica ${ }^{12}$. Por ello, "dado que la constitución es una constitución-en-acto, el texto promulgado es solo un primer paso, importante desde luego, pero sólo un primero paso en la tarea de hacer efectivos esos derechos" 13 .

Existe un optimismo moderado en el que se puede defender el texto aspiracional, entendido tanto sus limitaciones como sus ventajas de la lucha política en el que está inmerso. De acuerdo con esta visión, las constituciones aspiracionales son importantes, pero por sí solas insuficientes. Es necesario el apoyo social y político, el activismo judicial progresista y una cultura en pro de la protección de derechos ${ }^{14}$.

Las limitaciones del constitucionalismo aspiracional obedecen, en buena medida, a la tensión que se presenta entre democracia y derechos. García, siguiendo a Madison, Ely y Ackerman, indica que una constitución ideal debe lograr un máximo de participación democrática posible, compatible con el máximo de protección de derechos posible. El constitucionalismo democrático es aquel que logra este ideal ${ }^{15}$.

García identifica un constitucionalismo preservador, que se asocia con la limitación del poder y protección del statu quo. Y entre ese constitucionalismo

\footnotetext{
10 NEVES, Marcelo, Constitucionalización simbólica. Primera edición, Lima, Palestra editores. 2015, p. 135.

11 GARCÍA, Mauricio. "Constitucionalismo Aspiracional: Derecho, Democracia y Cambio Social en América Latina”. Análisis político No. 75. Bogotá. 2012, p. 93.

12 Ibíd.

13 Ibíd., p. 97.

14 Ibíd., p. 98.

15 Ibíd.
} 
El acceso limitado a la justicia administrativa frente a los requisitos de procediblidad

preservador y el constitucionalismo democrático se encuentran dos modelos intermedios, el aspiracional-judicial y el aspiracional-político. La calificación de judicial o político depende de la forma predominante como se intenta llevar a la práctica los mandatos constitucionales, es decir, a través de los jueces, en el primero caso, o a través del poder legislativo, en el segundo caso. Colombia es ejemplo del primer caso, Venezuela del segundo ${ }^{16}$.

Como puede verse, para García el constitucionalismo aspiracional es un punto intermedio entre el constitucionalismo preservador y el constitucionalismo democrático.

Ahora bien, el fundamento constitucional del derecho al acceso a la administración de justicia se encuentra en el preámbulo y los artículos 1, 2, 29, 228 y 229 de la Constitución Política.

Las normas constitucionales indican que la justicia es una finalidad del Estado colombiano (preámbulo). Así mismo, es un fin del Estado la garantía de principios, derechos y deberes consagrados en la Constitución, la convivencia pacífica y la vigencia de un orden justo (artículo 2). Igualmente, la administración de justicia es función pública, sus actuaciones son independientes, públicas y permanentes, y en ella prevalecerá el derecho sustancial (artículo 228). Por último, el artículo 229 constitucional dispone el derecho según el cual se garantiza a toda persona el acceso a la administración de justicia.

De lo anterior se observa que el acceso a la administración de justicia tiene diferentes connotaciones. Es un valor constitucional, entendido como un compromiso general del Estado con el fin de alcanzar la convivencia social y pacífica, asegurar la integridad del orden político, económico, jurídico y social justo. De este valor justicia desprende el deber del Estado consistente en prestar un buen servicio de justicia, de manera eficaz ${ }^{17}$.

De igual manera, es un derecho fundamental, pues implica "el reconocimiento al derecho a que se imparta justicia". ${ }^{18}$ Como derecho fundamental puede ser garantizado mediante la acción de tutela, y guarda una estrecha relación con el derecho al recurso judicial efectivo, así mismo, relacionado con la prevalencia del derecho sustancial sobre el procedimental, en el que la simple consagración formal de recursos y procedimientos no es suficiente, cuando los mismos no son idóneos y eficaces.

$16 \quad$ Ibíd., p. 99.

17 ARAUJO, Rocío. "Acceso a la justicia efectiva. Propuesta para fortalecer la justicia administrativa. Visión de derecho comparado" Revista Estudios Socio-Jurídicos. Bogotá. 2011, p. 251.

18 Ibíd., p. 252. 
El acceso a la administración de justicia también tiene un soporte normativo convencional. El artículo 25 de la Convención Americana sobre Derechos Humanos, indica que "toda persona tiene derecho a un recurso sencillo y rápido o a cualquier otro recurso efectivo ante los jueces o tribunales competentes, que la ampare contra actos que violen sus derechos fundamentales" 19 . A la luz de esta norma, no es efectivo un recurso ilusorio, inútil, que se resuelve en un contexto de carencia de independencia e imparcialidad, o por un órgano sin la capacidad para ejecutar su decisión, o en el evento en que se presenta un retardo injustificado ${ }^{20}$.

Para la Corte Constitucional, el derecho al acceso a la administración de justicia y el derecho a la tutela judicial efectiva son sinónimos, y pueden ser entendidos como "la posibilidad reconocida a todas las personas residentes en Colombia de poder acudir en condiciones de igualdad ante los jueces y tribunales de justicia, para propugnar por la integridad del orden jurídico y por la debida protección o el restablecimiento de sus derechos e intereses legítimos, con estricta sujeción a los procedimientos previamente establecidos y con plena observancia de las garantías sustanciales y procedimentales previstas en la ley, concretando una garantía real y efectiva, previa al proceso, que se logra a los individuos para asegurar la realización material de este, previniendo que en ningún caso se puede padecer de indefensión, entendida como la ausencia del derecho a alegar y la imposibilidad de defender en juicio los propios derechos" ${ }^{21}$.

El concepto señalado es tomado de la jurisprudencia de la Corte Constitucional, entre otros, en los planteamientos de las sentencias T-553 de 1995, T-406 de 2002, C-426 de 2002, T-1051 de 2002, T-1078 de $2012^{22}$.

A partir de este concepto, se desprenden unas obligaciones en cabeza del Estado, a saber: La de respetar, según la cual el Estado debe "abstenerse de adoptar medidas que tengan por resultado impedir o dificultar el acceso a la justicia o su realización"23. La de proteger, según la cual el Estado debe adoptar "medidas para impedir que terceros interfieran u obstaculicen el acceso a la administración de justicia del titular del derecho"24. Y la de realizar, según la

19 Conferencia Especializada Interamericana sobre Derechos Humanos. Convención Americana sobre Derechos Humanos. 22 de noviembre de 1969.

20 ARAUJO, Rocío. Op. cit., p. 254.

21 Ibíd.

22 Colombia. Corte Constitucional. Sala Séptima de Revisión de Tutelas. Sentencia de Tutela T-283. 16 de mayo de 2013. MP Jorge Ignacio Pretelt Chaljub. T-3.567.368.

23 Ibíd.

24 Ibíd. 
El acceso limitado a la justicia administrativa frente a los requisitos de procediblidad

cual el estado debe "(i) facilitar las condiciones para el disfrute del derecho y, (ii) hacer efectivo el goce del derecho" 25 .

Por último, señala que, para hacer efectivo del derecho a la administración de justicia, es necesario garantizar el derecho a la tutela judicial efectiva, el cual comprende: "(i) la posibilidad de los ciudadanos de acudir y plantear un problema ante las autoridades judiciales, (ii) que éste sea resuelto y, (iii) que se cumpla de manera efectiva lo ordenado por el operador jurídico y se restablezcan los derechos lesionados"26.

\section{El acceso a la jurisdicción lo de contencioso administrativo}

La Ley 1437 de 2011, Código de Procedimiento Administrativo y de lo Contencioso Administrativo (CPACA), establece, en su primera parte, las normas generales aplicables a todos los organismos y entidades que conforman las ramas del poder público, a los órganos autónomos e independientes y a los particulares, cuando cumplan funciones administrativas. En virtud del artículo 2 del CPACA, estos órganos y entidades que ejercen función administrativa reciben el nombre genérico de "autoridades".

La función administrativa ha sido entendida como "el conjunto de actividades particulares, disimiles entre sí, pero diversas de aquellas generales del estado y particulares propias de la función judicial y legislativa, que dan desarrollo directo a las finalidades del estado, consagradas de manera positiva en la Constitución Politica, que pueden ser desarrolladas por distintos sujetos de derecho, habilitados para ello, con el respeto y cumplimiento del ordenamiento jurídico superior"27.

La finalidad del CPACA es regular el ejercicio de la función administrativa. Y dentro del ejercicio de la función administrativa, el artículo 4 del CPACA indica las formas en que se da inicio a la actuación administrativa, a saber: mediante el ejercicio del derecho de petición, de interés general o particular, mediante el cumplimiento de una obligación o deber legal, u oficiosamente, por parte de las autoridades. A la actuación administrativa iniciada de esta forma, le serán aplicables las disposiciones generales de los artículos 34 y siguientes del CPACA, que establecen las reglas del procedimiento administrativo común y principal.

Existen numerosas normas que regulan actuaciones administrativas especiales, tales como las actuaciones administrativas disciplinarias (Ley 734 de 2002), la actuaciones administrativa de responsabilidad fiscal (Ley 610 de

\footnotetext{
25 Ibíd.

26 Ibíd.

27 MONTANA Plata Alberto. "La función pública. El Derecho Administrativo como Derecho de la Función Pública". "Fundamentos de Derecho Administrativo". Primera edición. Bogotá. Universidad Externado de Colombia. 2010, p. 124.
} 
2000), las actuaciones administrativas de tránsito (Ley 769 de 2002), las actuaciones administrativas de tipo tributario (Decreto 624 de 1989), entre otras. El CPACA es aplicable como regla general a las actuaciones administrativas, es decir, cuando no existan procedimientos especiales que dispongan otras reglas.

Ahora bien, el acto administrativo es la forma como finaliza, por regla general, el procedimiento administrativo. Y, para ser eficaz, el acto administrativo debe cumplir el principio de publicidad, ya sea mediante la notificación, comunicación o publicación. El acto administrativo de contenido particular y definitivo debe ser notificado mediante las formalidades señaladas en los artículos 67 y ss. del CPACA. Los actos administrativos de contenido particular son aquellos que se refieren a personas determinadas, y son de carácter definitivo cuando decidan directa o indirectamente el fondo del asunto, o hagan imposible continuar la actuación administrativa (artículo 43 del CPACA).

Con posterioridad a la notificación de los actos administrativos particulares y definitivos, el CPACA consagra los instrumentos jurídicos para que los ciudadanos impugnen las decisiones administrativas. A partir del artículo 74, el CPACA establece los recursos contra los actos administrativos: reposición, apelación y queja. De igual manera consagra la posibilidad de presentar la solicitud de revocatoria directa de los actos administrativos.

El término para interponer el recurso de reposición y el de apelación es de 10 días, contados a partir del día siguiente a la notificación de la decisión que se impugna. Con el recurso de queja se ataca la decisión que rechaza el recurso de apelación. Este recurso podrá interponerse ante el inmediato superior administrativo o funcional, para que sea él quien lo resuelva. El término para interponer este recurso es de 5 días, contados a partir del día siguiente a la notificación de la decisión que se impugna.

El artículo 76 del CPACA dispone que los recursos de reposición y de queja son facultativos. Por el contrario, señala que el recurso de apelación, cuando proceda, será obligatorio para acceder a la jurisdicción.

El artículo 138 del CPACA indica que toda persona que se crea lesionada en un derecho subjetivo amparado en una norma jurídica, podrá pedir que se declare la nulidad del acto administrativo particular, expreso o presunto, y se le restablezca el derecho; también podrá solicitar que se le repare el daño.

En concordancia con lo anterior, el artículo 161 del CPACA establece que cuando se pretenda la nulidad de un acto administrativo particular deberán haberse ejercido y decidido los recursos que de acuerdo con la ley fueren obligatorios.

Lo anterior quiere decir que, según las reglas generales, si un ciudadano quiere demandar un acto administrativo particular, previamente debe ejercer el recurso de apelación contra dicho acto. Si no lo hace, pierde la posibilidad de demandar el acto administrativo ante la autoridad judicial competente. 
El acceso limitado a la justicia administrativa frente a los requisitos de procediblidad

Una vez la administración de respuesta al recurso, el interesado podrá demandar el respectivo acto. Según el artículo 86 del CPACA, si transcurridos 2 meses contados a partir de la interposición de este recurso no se ha notificado decisión expresa sobre el mismo, se entenderá que la decisión es negativa. En este último evento se configura un acto administrativo presunto o ficto, que puede ser demandando, mediante la figura del silencio administrativo.

No obstante, a pesar de agotar los recursos obligatorios, el numeral primero del artículo 161 del CPACA contempla otro requisito de procedibilidad, que consiste en la conciliación prejudicial. Según esta norma, cuando los asuntos sean conciliables, "la conciliación extrajudicial constituirá requisito de procedibilidad de toda demanda en que se formulen pretensiones relativas a nulidad con restablecimiento del derecho, reparación directa y controversias contractuales" 28 .

El artículo 2.2.4.3.1.1.3. del Decreto 1069 de 2015, reglamentario del sector justicia, reitera lo señalado en el artículo 3 Decreto 1716 de 2009, y señala un plazo de hasta tres meses para adelantar la diligencia de conciliación prejudicial.

Una vez el interesado haya agotado los recursos obligatorios, y la conciliación prejudicial, podrá acudir ante el juez administrativo, en ejercicio de la acción de nulidad y restablecimiento del derecho.

Se observa entonces, que la posibilidad de acceder a la justifica administrativa implica cumplir una serie de cargas en cabeza de quien pretenda ejercer su derecho de acción para pedir la nulidad de un acto administrativo particular. El interesado en demandar deberá agotar el recurso de apelación. Según la norma podrá pasar hasta un término de 2 meses para que se entienda que hay una decisión desfavorable, objeto de demanda judicial. Pero adicional a ello, el interesado deberá promover la conciliación prejudicial, como requisito de procedibilidad; el procedimiento de la conciliación prejudicial podrá tardar hasta 3 meses, según la regulación administrativa citada.

\section{La suspensión provisional y la acción de tutela ${ }^{29}$}

Lo señalado en el capítulo anterior, deja en evidencia todo el recorrido que debe transitar quien pretenda demandar la nulidad de un acto administrativo particular.

28 Colombia. Congreso de la República. Ordinaria, Ley 1437, 18 de enero de 2011.

29 Para un desarrollo más amplio de este tema se puede consular JARAMILLO, Manuel. "Razón de Estado o Estado de razón. La justificación constitucional de los privilegios de la administración pública en Colombia: El privilegio de la decisión previa”, 2017, Bogotá, Universidad Nacional de Colombia. http://www.bdigital.unal.edu.co/ 57643/1/1088262399.2017.pdf 
Se podrá refutar que las ventajas de la nueva regulación de la suspensión provisional consagrada en el CPACA permite un acceso eficaz, oportuno y efectivo a la administración de justicia, en condiciones mucho mejores que las presentadas cuando estaba vigente el Decreto 01 de 1984 (CCA). Sin embargo, este argumento no es del todo cierto, por las razones que se explican a continuación.

El artículo 230 del CPACA señala que el interesado podrá hacer uso de las medidas cautelares, con la finalidad de "proteger y garantizar, provisionalmente, el objeto del proceso y la efectividad de la sentencia" ${ }^{30}$. En el caso de la acción de nulidad y restablecimiento del derecho, la medida cautelar por excelencia es la de suspensión provisional de los efectos de los actos administrativos. El artículo 233 del CPACA señala que cuando se solicita una medida cautelar, como lo es la suspensión provisional, la autoridad judicial dará traslado por el término de 5 días al demandado. Luego de este término, la autoridad tiene un plazo de 10 días para pronunciarse sobre ella.

Resumiendo hasta el momento, se observa que, si una persona quiere demandar un acto administrativo particular, deberá agotar los recursos obligatorios (que puede tardar hasta 2 meses) y agotar la conciliación prejudicial (que puede tardar hasta 3 meses). Y si quiere obtener un pronunciamiento cautelar, deberá esperar hasta 5 días y luego hasta 10 días más. Es necesario aclarar que estos términos se toman directamente de las normas, bajo una perspectiva ideal, sin tener en cuenta las vicisitudes de la congestión judicial que aumentan notablemente el tiempo de duración de los procedimientos judiciales.

En relación con ese término de traslado, se ha indicado que "por demás establecer (contrariamente a la regla según la cual el dictado de una medida cautelar debe hacerse "inaudita parte"), una fase de discusión y/o contradicción para adoptar las medidas cautelares [[no urgentes]] al señalársele el trámite de un término de traslado del escrito contentivo de la solicitud de medidas que deban materializarse -tanto dentro de los procesos propiamente contenciosos administrativos como dentro de los juicios constitucionales de tutela y populares-amén de requerirse restar caución, se contraponen a los presupuestas de necesidad por peligro actual (periculum in mora) y urgencia natural que guían a todo procedimiento precautelatorio" ${ }^{31}$. Esto indica que el término de urgencia que justifica el trámite cautelar de la suspensión provisional se pierde cuando se adicionan términos de discusión y contradicción a la contraparte de quien solicitó la medida.

\section{$30 \quad$ Ibíd.}

31 CHAVARRO, Roberto. "Análisis de las medidas cautelares en el Código de Procedimiento Administrativo y de lo Contencioso Administrativo colombiano, desde una perspectiva constitucional", ADVOCATUS edición especial No.18., 2012, Barranquilla, Universidad Libre, p. 41. 
El acceso limitado a la justicia administrativa frente a los requisitos de procediblidad

En otras palabras, aun haciendo uso de la suspensión provisional, el diseño normativo está establecido para que el actor deba esperar por lo menos 5 meses y 15 días para obtener un pronunciamiento judicial cautelar. Y es muy inusual que en el trámite de una medida cautelar se genere un espacio de controversia, ajeno a la naturaleza misma de este tipo de medidas.

De esta manera, se afirma que "pese a ser generosas las medidas cautelares señaladas por la Ley 1437 de 2011, pasarán muchos días para que los ciudadanos puedan acceder a ellas" 32 . Y ello es así porque "acceder a la Jurisdicción contencioso administrativo no es sencillo, debido a que siempre ha estado sometida, por decirlo de alguna manera, a trabas legales, bajo el entendido de que en muchos procesos debe cumplirse con ciertos requisitos que dilatan en el tiempo lo pretendido"33, tal como se indicó: recursos administrativos, esperar el silencio administrativo si no se responden los recursos, conciliación prejudicial, y luego las etapas previas dentro del proceso judicial. Por ello, algunos autores concluyen que "yendo más allá, la aplicabilidad o no de las medidas cautelares distan mucho de efectivizar el derecho o de garantizar la mentada tutela judicial efectiva"34.

Se podrá refutar que las personas podrán hacer uso de la acción de tutela, en aquellos casos donde se busque evitar un perjuicio irremediable. Lo anterior toda vez que si bien la tutela es improcedente ante la existencia de otro mecanismo ordinario de defensa judicial, la misma procede para evitar la configuración de perjuicios irremediables.

$\mathrm{Al}$ respecto es necesario tener en cuenta varios aspectos. En primer lugar, la jurisprudencia ha desarrollado un estándar muy estricto para demostrar la configuración de un perjuicio irremediable, entendido como aquel perjuicio que es inminente, grave, que requiere medidas urgentes e impostergables ${ }^{35}$.

En segundo lugar, se ha negado la procedencia de la acción de tutela para controvertir actos administrativos, ante la supuesta mayor eficacia de la suspensión provisional del CPACA.

32 LONDOÑO, Euclides, "Las medidas cautelares reguladas por la Ley 1437 de 2011 como instrumento para el desarrollo de la tutela jurisdiccional efectiva", Producto final de investigación "Las medidas cautelares reguladas por la Ley 1437 de 2011 como instrumento para el desarrollo de la tutela jurisdiccional efectiva", adelantada por el autor para optar al título de Magíster en Derecho, 2015, Medellín, Universidad Pontificia Bolivariana, p. 43.

https://repository.upb.edu.co/bitstream/handle/20.500.11912/2779/Art\%C3\% ADculo\%20de\%20Grado\%20Euclides\%20L.pdf?sequence=1 30 de abril de 2017.

33 Ibíd.

34 Ibíd., p. 44.

35 Colombia. Corte Constitucional. Sala Primera de Revisión de Tutelas. Sentencia de Tutela T-081. 15 de Febrero de 2013. MP. María Victoria Calle Correa. T-3.649.382. 
Para comprender lo anterior es necesario tener en cuenta que la suspensión provisional de los actos administrativos bajo el Decreto 01 de 1984 (CCA), tenía como requisito que la violación causada por el acto administrativo fuera una infracción manifiesta (artículo 152). Tal disposición le restaba eficacia a esta medida cautelar. Por tanto, una de las pretensiones con la nueva regulación contenida en el CPACA fue la de eliminar la expresión de la "manifiesta violación". De acuerdo con la nueva normatividad, no se exige una manifiesta infracción de las normas invocadas como sustento de la demanda.

La Corte Constitucional era consciente de la ineficacia de esa regulación de la suspensión provisional. Ejemplo de ello es la sentencia SU-039 de 1997, donde se concluyó, en relación con la regulación de la suspensión provisional en el CCA, lo siguiente: "pero lo que sí se advierte es que dados los términos estrictos en que el legislador condicionó su procedencia, no puede considerarse, en principio, como un mecanismo efectivo de protección de dichos derechos" 36 .

Bajo estas circunstancias se argumentaba a favor de la acción de tutela, como mecanismo de protección constitucional que sí protegía de manera eficaz los derechos que no eran protegidos mediante la suspensión provisional.

En relación con la suspensión provisional de acuerdo con el CPACA, mediante una aclaración de voto de un auto, el magistrado Alberto Yepes Barreiro indicó: "La suspensión provisional, junto con los otros medios de cautela que diseñó el legislador en la Ley 1437 de 2011, son, en mi concepto, medios idóneos y eficaces con los que cuenta hoy el juez de lo contencioso administrativo para asegurar, cuando ellos estén en juego, la protección, garantía y restablecimiento de los derechos e intereses de quienes acuden a los diversos medios de control, incluidos o en especial, los derechos fundamentales"37. Es decir, a juicio de esta aclaración de voto, la suspensión provisional es un medio idóneo y eficaz, dirigido a garantizar los derechos e intereses, incluso los derechos fundamentales.

Existen argumentos fuertes para defender la nueva regulación de la suspensión provisional en el CPACA, en comparación de la regulación en el CCA, tal como se ha visto; no obstante, cuando se analiza la suspensión provisional en el contexto del diseño actual de los requisitos previos a demandar, es decir, recursos y conciliación, se observa que la suspensión provisional, incluso según el nuevo código, no logra ser tan eficaz como se dice. Y si se compara la acción de tutela con la suspensión provisional de acuerdo con el CPACA, el simple cotejo de término entre una y otra permite concluir que la medida cautelar referida no supera en

36 Colombia. Corte Constitucional. Sala Plena. Sentencia de Unificación SU-039. 3 de Febrero de 1997. MP. Antonio Barrera Carbonell. T-84771.

37 Colombia. Consejo de Estado. Sección Quinta. Auto 2013-00040, 31 de Octubre de 2013. MP. Lucy Jeannette Bermúdez Bermúdez. Radicado No. 110010328000201300040. 
El acceso limitado a la justicia administrativa frente a los requisitos de procediblidad

eficacia a la acción de tutela. El término de 5 meses y 15 días del medio de control de nulidad y restablecimiento del derecho compite con el término de 10 días en el que se debe decidir una acción de tutela en primera instancia.

La idea explicita en la aclaración de voto, según el cual la suspensión provisional es un medio idóneo y eficaz para garantizar derechos, incluso los de carácter fundamental, ha servido como fundamento para negar la procedencia de la acción de tutela, ante la idea que defiende la eficacia de la nueva regulación de la suspensión provisional. Por ejemplo, la Corte Constitucional ha señalado que, en referencia con un acto administrativo, "es preciso recalcar que esta decisión, es susceptible de ser demandada ante la jurisdicción contencioso administrativa mediante la acción de nulidad y restablecimiento del derecho, dentro de la cual puede solicitar la suspensión provisional de los actos administrativos proferidos por la Contraloría General de la República y que la reiterada jurisprudencia de esta Corporación ha considerado idónea"38.

En el mismo sentido, el Consejo de Estado también ha manifestado que con la finalidad de:

"salvaguardar la naturaleza subsidiaria y residual de la acción de tutela, y a su vez, el respeto de los mecanismos especialmente diseñados por el legislador para resolver determinadas controversias, en criterio de la Sala no es desproporcionado exigirle a la sociedad accionante que en los términos y condiciones legalmente establecidos, acuda al medio de control de nulidad y restablecimiento del derecho y a las medidas cautelares previstas en la Ley 1437 de 2011, para controvertir las referidas resoluciones" ${ }^{39}$.

De igual manera, ha manifestado que los actos administrativos:

"son susceptibles de ser atacados y enjuiciados ante la jurisdicción de lo contencioso administrativo, mediante el ejercicio del medio de control de nulidad y restablecimiento del derecho. En dicho trámite y a título de medida cautelar puede pedir la suspensión provisional de los efectos de dicho acto que considera lesiona el ordenamiento superior. Este mecanismo cautelar es apto e idóneo para la protección de los derechos fundamentales, y además es expedito, toda vez que la medida de suspensión provisional debe ser resuelta por el juez de lo contencioso administrativo luego del auto admisorio de la demanda" ${ }^{\text {. }}$.

38 Colombia. Corte Constitucional. Sala Octava de Revisión. Sentencia de Tutela T-030. 26 de enero de 2015. MP. Martha Victoria Sáchica Méndez. T-4455240.

39 Colombia. Consejo de Estado. Sección Segunda, Subsección “B”. Sentencia de Tutela No. 02275-01. 20 de agosto de 2014. MP. Gerardo Arenas Monsalve. 25000-23-42-000-201402275-01.

40 Colombia. Consejo de Estado. Sección Quinta. Sentencia de Tutela. 6 de Noviembre de 2014. MP. Susana Buitrago Valencia. 17001-23-33-000-2014-00295-01. 
Por lo anterior, se puede afirmar que una vez analizados los parámetros jurisprudenciales sobre el acceso a la administración de justicia, en especial el que señala la obligación sobre el Estado de abstenerse de adoptar medidas que tengan por resultado impedir o dificultar el acceso a la justicia o su realización, el deber de facilitar las condiciones para el disfrute del derecho y el de hacer efectivo el goce del derecho, se observa que en el caso concreto del acceso a la administración de justicia, cuando se demanda la nulidad y restablecimiento de un acto administrativo, no se cumplen.

Esto debido a que el diseño institucional consistente en agotar los recursos y luego tener que conciliar, en realidad constituyen medidas encaminadas a impedir o dificultar el acceso a la administración de justicia. De igual manera, estos requisitos de procedibilidad no facilitan las condiciones de disfrute del derecho al acceso a la justicia.

Aunque antes se defendía la procedencia de la acción de tutela, para contrarrestar la ineficacia de los mecanismos de control sobre los actos administrativos particulares, en la actualidad la jurisprudencia ha negado la procedencia de la tutela, bajo argumentos que no tienen en cuenta la realidad institucional ineficaz del acceso a la administración de justicia en la jurisdicción de lo contencioso administrativo, tal como se demostró en el medio de control de nulidad y restablecimiento del derecho.

La determinación de negar por improcedente la tutela, cuando procede el mecanismo de nulidad y restablecimiento del derecho, tiene como fundamento el artículo 6 del Decreto 2591 de 1991, que señala: "La acción de tutela no procederá: 1. Cuando existan otros recursos o medios de defensa judiciales, salvo que aquélla se utilice como mecanismo transitorio para evitar un perjuicio irremediable. La existencia de dichos medios será apreciada en concreto, en cuanto a su eficacia, atendiendo las circunstancias en que se encuentra el solicitante"41. Según la primera parte de la disposición, la acción de tutela es improcedente cuando existen otros medios de defensa judicial, por lo tanto, ante la procedencia de la acción de nulidad y restablecimiento del derecho, la respuesta es negar la tutela con fundamento en la citada norma. Sin embargo, la segunda parte de la disposición también indica que la existencia los medios ordinarias de defensa será analizada en el caso concreto, teniendo en cuenta las circunstancias del solicitante y su eficacia.

Ello quiere decir que la simple existencia del mecanismo ordinario de defensa no es suficiente cuando dicho medio no es eficaz. En otras palabras, en un caso concreto podrá determinarse que si el mecanismo ordinario de defensa es ineficaz la tutela es procedente.

$41 \quad$ Colombia. Presidencia de la República. Decreto Ley 2591, 19 de noviembre de 1991. 
El acceso limitado a la justicia administrativa frente a los requisitos de procediblidad

Este segundo elemento del artículo 6 del Decreto 2591 de 1991 parce ser ignorado en los fallos que niegan la procedencia de la tutela por la simple existencia del mecanismo ordinario de defensa.

Lo que se ha demostrado durante el presente escrito es precisamente que la acción de nulidad y restablecimiento del derecho, con suspensión provisional, no es eficaz, por la existencia de unos requisitos de procedibilidad (recursos y conciliación), que tienden a dilatar el pronunciamiento cautelar o definitivo del juez. Su ineficacia también tiene como sustento el periodo de controversia previa para resolver la medida cautelar que establecido el CPACA (5 días de traslado y 10 días para resolver).

Si la acción de nulidad y restablecimiento del derecho realmente se aprecia en el escenario institucional concreto, se hace evidente su ineficacia. Ineficacia frente a la cual se puede defender la procedencia de la acción de tutela.

Se ha sobrevalorado la eficacia de la suspensión provisional bajo las reglas del CPACA, ignorando la realidad institucional y el diseño normativo, que establece diferentes cargas en cabeza de quien pretenda demandar. Con fundamento en esa supuesta eficacia del mecanismo ordinario de defensa (nulidad y restablecimiento del derecho con suspensión provisional), se ha negado la procedencia de la acción de tutela, mecanismo realmente eficaz. En otras palabras, lo ineficaz se presenta como eficaz, y lo realmente eficaz se califica de improcedente.

\section{Conclusiones}

La regulación de la suspensión provisional en la ley 1437 de 2011 tiene avances importantes en comparación con la regulación del Decreto 01 de 1984, como lo es el hecho de que el juez contencioso administrativo no deba observar una violación manifiesta del ordenamiento jurídico para otorgar esta medida cautelar. La obligación de evidenciar una manifiesta violación hacía que en la práctica fuera improcedente acceder a la suspensión provisional de un acto administrativo.

Sin embargo, la nueva regulación normativa no satisface el estándar jurisprudencial sobre el acceso a la administración de justicia administrativa. Esto se debe a que el diseño normativo para poder demandar un acto administrativo de carácter particular, a través del medio de control de nulidad y restablecimiento del derecho, presenta diferentes cargas desproporcionadas en cabeza del futuro demandante. En primer lugar, quien pretenda demandar un acto administrativo particular debe agotar, por regla general, el recurso de apelación, trámite que puede tardar hasta 2 meses. Adicional a ello, debe agotar la conciliación prejudicial, y esperar hasta 3 meses para que se surta dicha actuación. Una vez el demandante haya agotado estos requisitos de procedibilidad, podrá presentar la demanda de nulidad y restablecimiento del derecho, y pedir la suspensión 
provisional de los actos demandados. Pero para que el juez decida la suspensión provisional, deberá esperar por lo menos 5 días de traslado para el demandado, y 10 días más que otorga la ley para que el juez decida la suspensión provisional. Por lo anterior, se observa que no se respetan las obligaciones y deberes en cabeza del Estado respecto del derecho de acceso a la administración de justicia, tales como la obligación de abstenerse de adoptar medidas que tengan por resultado impedir o dificultar el acceso a la justicia o su realización, el deber de facilitar las condiciones para el disfrute del derecho, y el deber de hacer efectivo el goce del derecho. Por el contrario, el Estado colombiano ha establecido medidas para impedir y dificultar el acceso, no ha facilitado dicho acceso. En síntesis, ha establecido medidas que impiden hacer efectivo el goce del acceso a la jurisdicción.

Ante dicha situación, la alternativa judicial de quien pretende impugnar vía judicial un acto administrativo, y quiere obtener un pronunciamiento eficaz y oportuno, es la acción de tutela.

La acción de tutela procede, aunque proceda también el medio ordinario de defensa, ante la existencia de un perjuicio irremediable, y bajo un estándar jurisprudencial muy alto, donde pocos casos pueden reunir los requisitos de inminencia, gravedad, urgencia e impostergabilidad.

Según la regulación del artículo 6 del Decreto 2591 de 1991, la tutela igualmente procede cuando el medio ordinario de defensa es ineficaz. Y durante lo largo de este escrito se ha demostrado que el medio de control de nulidad y restablecimiento del derecho con suspensión provisional es ineficaz.

De esta manera, existen las herramientas normativas para determinar que en un caso concreto, siendo procedente el medio ordinario de defensa, y aunque no se presente un perjuicio irremediable, es procedente la acción de tutela para controvertir, o al menos suspender, los efectos de un acto administrativo particular, obteniendo un pronunciamiento oportuno y eficaz.

Desafortunadamente, la jurisprudencia ha ignorado sistemáticamente el análisis de la eficacia del medio ordinario de defensa como lo es el de nulidad y restablecimiento del derecho con suspensión provisional.

Ciertamente la acción de tutela ha derivado en abusos y en congestión judicial, lo que ha motivado la existencia de estándares jurisprudenciales ampliamente formalistas para determinar su improcedencia, pero ello no es razón suficiente para ignorar el diseño institucional ineficaz de la suspensión provisional de los actos administrativos que tiene como consecuencia negar el acceso a la jurisdicción.

De esta manera, se puede afirmar que la acción de tutela es el mecanismo adecuado para obtener un pronunciamiento judicial eficaz y oportuno en relación con la impugnación de un acto administrativo particular, contrarrestando al 
El acceso limitado a la justicia administrativa frente a los requisitos de procediblidad

ineficaz mecanismo ordinario de defensa de nulidad y restablecimiento del derecho, medio ordinario que está circunscrito en un escenario de requisitos previos retardatorios.

De esta manera, la jurisprudencia no debe seguir calificando lo ineficaz de eficaz, ni lo eficaz de improcedente. Pues ante dichas disquisiciones formalistas los ciudadanos se quedan desamparados frente al abuso de las autoridades administrativas.

Si las normas constitucionales que consagran derechos, deberes y obligaciones no tienen instrumentos efectivos de protección y garantía en la jurisdicción de lo contencioso administrativo, es válido concluir que nuestro constitucionalismo dista mucho de ser un constitucionalismo democrático, y por el contrario, se acerca más a un constitucionalismo nominal o retórico, con un acceso limitado a la justicia administrativa.

\section{Referencias bibliográficas}

\section{Normas}

Conferencia Especializada Interamericana sobre Derechos Humanos. Convención Americana sobre Derechos Humanos. 22 de noviembre de 1969.

Colombia. Congreso de la República. Ley ordinaria 1437, 18 de enero de 2011.

Colombia. Presidencia de la República. Decreto ley 2591, 19 de noviembre de 1991.

Colombia. Presidencia de la República, Decreto reglamentario 1069, 26 de mayo de 2015.

Colombia. Presidencia de la República, Decreto reglamentario 1716, 14 de mayo de 2009.

\section{Jurisprudencia}

Colombia. Consejo de Estado. Sección Quinta. Auto 2013-00040, 31 de Octubre de 2013.MP Lucy Jeannette Bermúdez Bermúdez. Radicado No. 110010328000201300040.

Colombia. Consejo de Estado. Sección Segunda, Subsección “B”. Sentencia de Tutela No. 02275-01. 20 de agosto de 2014. MP. Gerardo Arenas Monsalve. 25000-23-42-0002014-02275-01.

Colombia. Consejo de Estado. Sección Quinta. Sentencia de Tutela. 6 de Noviembre de 2014. MP. Susana Buitrago Valencia. 17001-23-33-000-2014-00295-01.

Colombia. Corte Constitucional. Sala Plena. Sentencia de Unificación SU-039. 3 de Febrero de 1997. MP. Antonio Barrera Carbonell. T -84771.

Colombia, Corte Constitucional. Sala Plena. Sentencia de Constitucionalidad C-415, 6 de junio de 2012, MP. Mauricio González Cuervo, Expediente No. D-8820.

Colombia. Corte Constitucional. Sala Primera de Revisión de Tutelas. Sentencia de Tutela T-081. 15 de Febrero de 2013. MP. Maria Victoria Calle Correa. T-3.649.382. 
Colombia. Corte Constitucional. Sala Séptima de Revisión de Tutelas. Sentencia de Tutela T-283. 16 de mayo de 2013. MP. Jorge Ignacio Pretelt Chaljub. T-3.567.368.

Colombia. Corte Constitucional. Sala Octava de Revisión. Sentencia de Tutela T-030. 26 de enero de 2015. MP. Martha Victoria Sáchica Méndez. T-4455240.

\section{Doctrina:}

ARAÚJO, Rocío. "Acceso a la justicia efectiva. Propuesta para fortalecer la justicia administrativa. Visión de derecho comparado" Revista Estudios Socio-Jurídicos. Bogotá. 2011.

CHAVARRO, Roberto. "Análisis de las medidas cautelares en el Código de Procedimiento Administrativo y de lo Contencioso Administrativo colombiano, desde una perspectiva constitucional", ADVOCATUS edición especial No.18., Barranquilla, Universidad Libre. 2012.

GARCÍA, Mauricio. “Constitucionalismo Aspiracional: Derecho, Democracia y Cambio Social en América Latina”. Análisis político No. 75. Bogotá. 2012.

GARCÍA, Yezid, GÓMEZ, Lina, PUENTES, Elizabeth. "El nuevo régimen de las medidas cautelares contempladas en la Ley 1437 de 2011 y su aplicación en la jurisdicción contenciosa administrativa”. Derecho y Políticas Públicas, Volumen 16 No. 20. Bogotá, Universidad Cooperativa de Colombia, 2014.

GARGARELLA, Roberto. "El constitucionalismo latinoamericano y la "sala de máquinas" de la Constitución (1980-2010)”. Gaceta Constitucional No. 48. Bogotá. 2011.

GONZÁLEZ, Sergio, "Capítulo XI - Medidas Cautelares", Código de Procedimiento Administrativo y de lo Contencioso Administrativo, Ley 1437 de 2011, comentado y concordado, Primera edición. Bogotá. Universidad Externado de Colombia. 2013.

LONDOÑO, Euclides, "Las medidas cautelares reguladas por la ley 1437 de 2011 como instrumento para el desarrollo de la tutela jurisdiccional efectiva”, Medellín, Universidad Pontificia Bolivariana. 2015 https://repository.upb.edu.co/bitstream/ handle/20.500.11912/2779/Art\%C3\%ADculo\%20de\%20Grado\%20Euclides\%20L. pdf?sequence $=130$ de abril de 2017.

MONTAÑA, Alberto. "La función pública. El Derecho Administrativo como Derecho de la Función Pública". "Fundamentos de Derecho Administrativo". Primera edición. Bogotá. Universidad Externado de Colombia. 2010.

NEVES, Marcelo, Constitucionalización simbólica. Primera edición, Lima, Palestra editores. 2015.

RESTREPO, Manuel. "La necesidad de ampliar la tutela cautelar judicial en el proceso contencioso administrativo”. Revista Estudios Socio-Jurídicos, Bogotá, No. 7 (2). Universidad del Rosario. 2005.

UPRIMNY, Rodrigo, RODRÍGUEZ, César. "Constitución y modelo económico en Colombia: hacia una discusión productiva entre economía y derecho". Debates de coyuntura económica. Bogotá. 2006. 